\title{
TRANSPORT
}

\section{ОСОБЛИВОСТІ АВТОМАТИЗАЦЇ̈ КОНТРОЛЮ ТЕХНІЧНОГО СТАНУ МОРСЬКОГО ТРАНСПОРТУ}

\author{
Коломієць Оксана Михайлівна \\ Державний університет інфраструктури та технологій, Аспірант, \\ Україна, Київ, \\ orcid.org/0000-0001-7161-8957
}

DOI: https://doi.org/10.31435/rsglobal_ws/31032019/6400

\section{ARTICLE INFO}

Received: 18 January 2019

Accepted: 22 March 2019

Published: 31 March 2019

\section{KEYWORDS}

metods;

automation;

control;

technical condition;

marine transport;

Soft-ware;

a priori information \begin{abstract}
The article analyzes the principles of automation of the control of the technical condition of water transport vehicles, which has been determined: the principle of coherence; the principle of integration; Principle of independence of execution.

It is determined that the most effective strategy is to improve the methods of automated control of the technical condition of water transport vehicles, which, unlike existing ones, is based on Markov processes, the Runge-Kutta method of numerical solution of the system of Kolmogorov differential equations and a priori information about the intensity of transitions from state to state.

Using the software implementation of the model significantly improves performance due to the ergonomics of the interface and reduced number of operations.
\end{abstract}

Citation: Kolomiyets Oksana Mikhailovna. (2019) Features of Automation of Control of Technical Status of Marine Transport. World Science. 3(43), Vol.1. doi: 10.31435/rsglobal_ws/31032019/6400

Copyright: (C) 2019 Kolomivets Oksana Mikhailovna. This is an open-access article distributed under the terms of the Creative Commons Attribution License (CC BY). The use, distribution or reproduction in other forums is permitted, provided the original author(s) or licensor are credited and that the original publication in this journal is cited, in accordance with accepted academic practice. No use, distribution or reproduction is permitted which does not comply with these terms.

Вступ. Аналіз стану безпеки руху засобів морського та водного транспорту України дозволяє зробити висновок про те, що саме людський фактор є найбільш значною причиною аварійності на морському та річному флоті за останні роки. Відомо, що на всіх видах транспорту існує така ж сама обставина. Це пояснюється складністю транспортних засобів, збільшенням інтенсивності транспортних перевезень, проблемами в системі підготовки фахівців та ін.

Тому дослідження, які спрямовані на «...розроблення методів підвищення ефективності контролю технічного стану транспортної техніки, встановлення закономірностей змінювання параметрів технічного стану у процесі експлуатації, впровадження методів і засобів діагностування та прогнозування технічного стану засобів транспорту, що забезпечують високу ефективність їх використання та надійність роботи» є актуальними [1].

Постановка проблеми в загальному вигляді. Таким чином, незважаючи на розвиток транспортної галузі України, водного транспорту зокрема, актуальним є наукове завдання удосконалення існуючих та розробки нових моделей та методів автоматизації контролю технічного стану (ТC) суден у різноманітних умовах експлуатації з метою впровадження їх в математичному та програмному забезпеченні АРM в Integrated Bridge System, вирішенню цього завдання і присвячена стаття.

Аналіз останніх досліджень i публікацій. Питання технічної експлуатації, обслуговування і ремонту засобів водного транспорту висвітлюється у роботах В.В. Паніна, 
М.М. Цимбала, Б.В. Васильєва, Ю.Г. Дейнего, О.А. Оніщенко, С.I. Сербіна, В.І. Богомї, Д.І. Севастєєва, С.Р. Смирнова та ін.

У тому числі, щодо питань автоматизації контролю технічного стану засобів водного транспорту у різноманітних умовах експлуатації відомі роботи вчених: І.П. Атаманюка, I.О. Мачаліна, В.М. Глушкова, М.З. Згуровського, О.Г. Івахненка, В.Д. Кудрицького, Р.К. Мурасова, В.С. Пугачова, Р.А. Варбанця та ін. Але коло проблем звужується досить повільно. Це обумовлено багатьма факторами, в тому числі ї складністю завдання.

Таким чином, актуальність досліджень визначається невідповідністю існуючих методів автоматизації реальним умовам функціонування. Тобто, на практиці не існує такого підходу, який грунтується на сучасному науково-обгрунтованому апарату та дає відповідні результати.

Варте підкреслити те, що в умовах інтенсивного розвитку інформаційних технологій, які на високому рівні дозволяють вирішувати будь-які завдання за рахунок автоматизації логічною та закономірною є тенденція поєднання та автоматизації всіх функцій на судні. В тому числі ї тих, які пов'язані з контролем технічного стану.

Тим більше, сучасної $\epsilon$ тенденція впровадження ідей створення інтегрованого обладнання ходової рубки, яка полягає в створені так званої інтегрованої мостикової системи (Integrated Bridge System) [2, 3].

Дана система об'єднує системи навігації, управління рухом, управління енергетичною системою тощо. На сучасних суднах такі комп'ютерні комплекси мають назву - інтегрованих мастикових систем (Integrated Bridge System). Дані системи будуються, як правило, за двома принципами технології інтегрування: централізована система (обробка інформації та формування команд управління в блоці центрального комп'ютера); децентралізована або розподілена система (використовується технологія багатомодульності). Дані системи надають оператору (рулевому) інформацію о параметрах роботи двигуна, енергетичного обладнання тощо, але рішення про визначення технічного стану він повинен приймами особисто суб'єктивне.

Тобто недоліком при оцінці технічного стану в даному випадку, як завжди є так званий «людський фактор».

Мета статті. Таким чином, з метою розвитку технології Integrated Bridge System та автоматизації процесу контролю технічного стану засобів водного транспорту доцільне розробити ефективні моделі та методи для математичного та програмного забезпечення в інтегрованих мастикових системах.

Результати дослідження. Моніторинг технічного стану здійснюється за рахунок різноманітних суб'єктів, поступає великий потік інформації який систематизується не в повному обсязі. Ця інформація ніяк наглядно не представляється. На даний час немає централізованого автоматизованого робочого міста (АРМ) для моніторингу відповідної інформації. Тому актуально створити централізований ресурс, для систематизації даних, формування бази знань та наглядного зображення технічного стану судна в різноманітних умовах (рис. 1).

Дослідження дозволяє зробити висновок про те що найбільш доцільним $\epsilon$ автоматизоване та централізоване управління процесом контроля ТС через спеціалізований інформаційний ресурс.

\section{Математична формалізація наукового завдання}

Математична формалізація наукового завдання має наступній вигляд (1).

Знайти:

$$
\begin{gathered}
\varepsilon=\left\{\rho_{1}, \rho_{2}, \ldots \rho_{n}\right\} ; \\
\xi \in\{\varepsilon, \tau, v\} \\
\omega:\left\{\begin{array}{c}
\forall \delta\langle\mu, \theta, \Omega\rangle \\
\xi \notin \delta \\
\beta \in\left\langle b_{1}, b_{2}, b_{3}, b_{4}\right\rangle
\end{array},\right.
\end{gathered}
$$

де: $\omega$ - множина моделей та методів, які реалізовані в АРM Integrated Bridge System;

$\delta$ - множина елементів бази знань;

$\mu$ - множина ТС;

$\theta$ - множина елементів бази знань по вирішенню проблем;

$\Omega$ - множина елементів оцінки термінів вирішення проблем; 
$\xi$ - множина функцій оператора;

$v$ - множина функцій капітана;

$\rho_{\mathrm{i}}$ - візуальна інформація;

$\varepsilon$ - множина технічних датчиків ;

$\tau-$ функція редагування бази знань;

$\beta$ - множина типів проблем зміни ТС;

$b_{1}$ - технічний стан 1 ;

$b_{2}$ - технічний стан 2 ;

$b_{3}-$ технічний стан 3 ;

$b_{4}$ - інші.
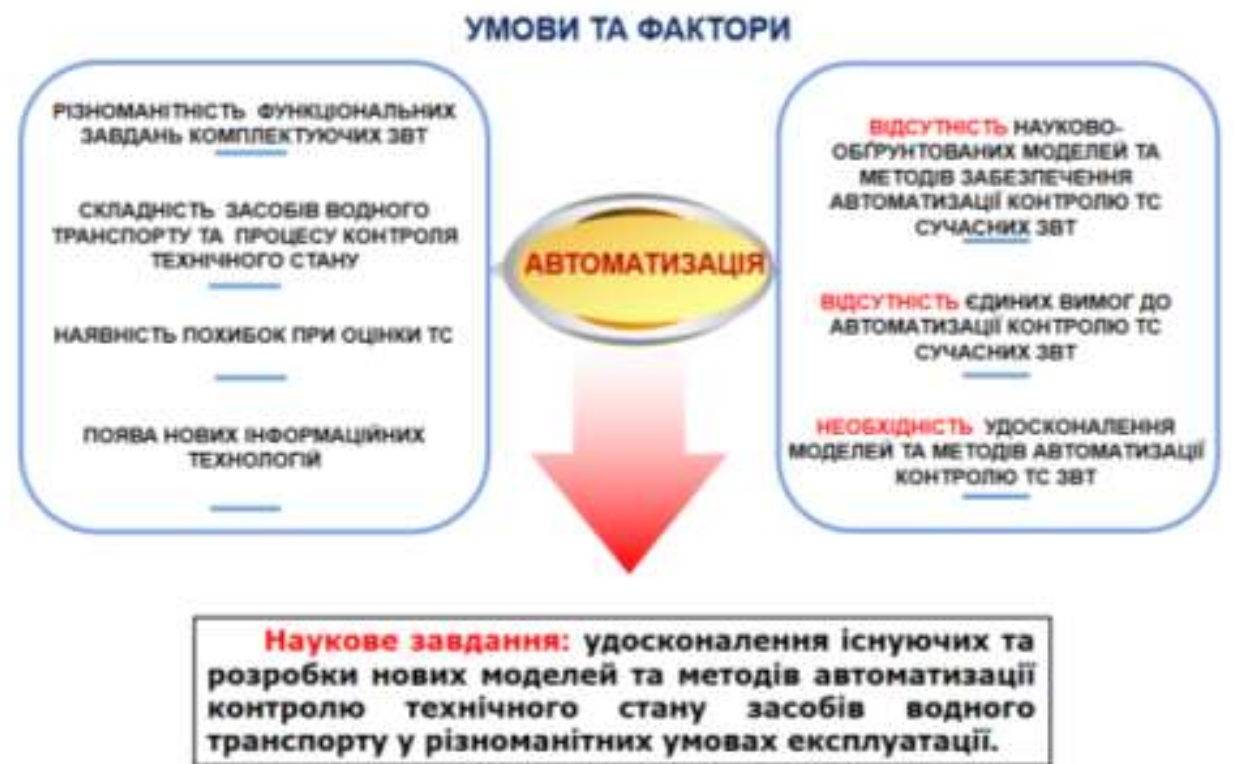

Рис. 1. Проиес зв'язку датчиків з АРМ

Таким чином, ідея централізованого управління процесом обміну інформації в системі моніторингу технічного стану судна дозволяє підвищити швидкість обміну інформацією та підвищити ефективність прийняття рішень щодо вирішення проблем безпеки судноплавства.

Наукова новизна одержаних результатів полягає в тому, що розроблено евристична модель оперативного визначення технічного стану засобів водного транспорту в умовах відсутності достовірної статистичної інформації, відмінною особливістю якої є використання в опису процесу зміни стану ланцюжків причино-наслідкових зв'язків та продукційної моделі оператору переходу; це дозволяє значно скоротити обчислювальні витрати та час на визначення стану.

Евристична модель оперативного визначення технічного стану ЗВТ в умовах відсутності достовірної статистичної інформації.

У сучасних умовах розвитку науки, впровадження іiі результатів в практику пов'язані зі створенням таких систем, які автоматично витягають із середовища необхідні дані, переробляють їх, координують дії щодо наявних цілей та володіють при цьому здатністю обробляти значні масиви інформації, а також функціонувати, не маючи постійних контактів 3 людиною-оператором. Це в повній мірі відноситься і до систем автоматичної (автоматизованої) оцінки технічного стану засобів водного транспорту [3].

В загальному випадку такі системи необхідні в умовах, коли віддаленість дослідника не дозволяє йому своєчасно реагувати на зміни обстановки в районі об'єкта досліджень при роботі в середовищах, небезпечних для людини (наприклад, через радіацію, високих температур та ін.). А згідно теми досліджень в умовах, які вимагають додатково складних і багато вартісних підготовчих робіт (наприклад, повної або часткової розбірки агрегатів судна, при обробці великих масивів вихідної різнорідної інформації, пов'язаною з графіком заходів щодо технічної експлуатації судна. 
Наведені міркування висувають необхідність застосування якісно нових методів вирішення завдань, шляхом моделювання процесу мислення людини, методів, які забезпечать ефективне розв'язання особливо складних завдань, зокрема контролю технічного стану обладнання судна, в умовах неповної, недостатньої поточної інформації. Такі завдання виникають в умовах функціонування систем, що залежать від багатьох різнорідних змінних. Методи вирішення таких завдань в умовах, коли через складність або недостатності інформації не можна точно окреслити межі їх застосування та оцінити допустимі помилки, називають евристичними [3].

Евристичні методи, на відміну від строгих, припускають вивчення принципової переробки інформації, що здійснюється людиною не різних етапах його діяльності при вирішенні різних завдань, і побудова на цій основі комп'ютерних програм. Цей процес зазвичай називають евристичним програмування.

Слід зазначити, що характерною особливістю евристичного програмування $\epsilon$ широке вивчення методів роботи людини при вирішенні завдання в умовах неповної поточної інформації, особливостей накопичення даних про процес вирішення аналогічних завдань; формування досвіду i моделювання всього процесу переробки інформації шляхом розчленування його на елементарні підетапи.

Евристичні рішення принципово відрізняються від строгих. Основним в їх утворенні $\epsilon$ процедури пошуку взаємопов'язаності компонентів рішення, який починається в умовах відсутності відповідного алгоритму та будь-яких відомостей про існування рішення і його єдності. При цьому при процесі пошуку іноді проводиться додатковий збір необхідної інформації. Загально прийнято, що центральне місце в теорії евристичних рішень займають проблеми впізнання ситуацій та явищ навколишнього світу, що являють собою звернення приватних проблем розпізнавання образів [4].

Важливе значення у створенні теорії евристичних рішень уявляє дослідження елементарних інформаційних процесів на різних рівнях. Під дослідженням елементарних інформаційних процесів зазвичай розуміють «факторизацію», дроблення, програмування розумового процесу, а головним завданням дослідження є виявлення правил об'єднання цих елементарних інформаційних процесів у складні програми. Це безумовно віддзеркалює один 3 основних принципів системного підходу - принципу декомпозиції [4].

\section{Метод оцінки ефективності моделей автоматизації.}

Уявлення абстрактної моделі виведення у вигляді розгалуженого процесу або, що те ж саме, у вигляді орієнтованого графа дозволяє виявити ряд властивостей моделі, звертаючи до теорії графів $[5,6]$.

Нехай корінь вузлова точка розгалуженого процесу, у яку входить одна операція (гілка) попереднього етапу і виходить $Z$ альтернатив (гілок), породжуваних операціями на даному етапі.

Вважаємо, що на кожному етапі кожен корінь має на виході $Z$ гілок, тоді загальна кількість гілок розгалуженого процесу, що з'являється на $U$-му етапі, дорівнює $Z^{U}$, а загальна кількість гілок цього дерева $[7,8]$

$$
V(U)=Z\left(Z^{U}-1\right) /(Z-1) .
$$

Позначимо коріння їх адресами, уявними індексами коренів попереднього етапу (крім нульового), що породили розглянутий корінь, і його порядковим номером зверху вниз.

Наприклад, корінь $S_{j_{1} j_{2}} \cdots_{k_{-1} j_{k}}$ породжений коренем попереднього етапу i його порядковий номер $S_{j_{1} j_{2}} \cdots_{j_{k-1}}$, та його порядковий номер $k$.

Позначимо операції через $r$ з індексом, рівним індексу кореня результату. Для скорочення запису в ряді випадків позначимо складний індекс $j_{1} j_{2} \ldots j_{k-1} j_{k}$, як $j_{k}$. Неважко бачити, що нижній індекс у крайній правій букви означає етап, на якому розглядається дані корінь. Потім також, що в ряді випадків складний індекс кореня $S_{j_{1} j_{2}} \cdots j_{k}$ можна інтерпретувати як деяке число, записане за певним модулем [9, с.228].

Отриманий граф в результаті застосування того або іншого тесту називають усіченим розгалуженим процесом [5]. Розглянемо модель ефективність пошуку рішень при використанні усіченого розгалуженого процесу. Нехай $t_{1}, t_{2}, t_{k+1}$ - кількість усічених коренів розгалуженого процесу на 1 -му, 2-му, ... $U$ - му, $(U+1)$ - му етапах рішення кількість, а $Z$ - кількість застосовуваних операції. Тоді кількість гілок на цих етапах буде відповідно дорівнювати: 


$$
\begin{gathered}
v_{1}=Z-t_{1}, \\
v_{2}=\left(Z-t_{1}\right) Z-t_{2}, \\
\ldots \ldots \ldots \ldots \ldots \ldots \ldots \ldots \ldots \ldots \ldots \ldots \ldots \ldots \ldots \\
v_{U}=Z^{U}-t_{1} Z^{U-1}-\ldots-t_{U-1} Z-t_{U}, \\
v_{U+1}=Z^{U+1}-t_{1} Z^{U}-\ldots-t_{U-1} Z^{2}-t_{U} Z-t_{U+1} .
\end{gathered}
$$

Зрозуміло, якщо на деякому, наприклад на $U$-му етапі, досягнуто рішення, то на наступному $U+1$-му етапі, на всі гілки слід відсікти, тобто

$$
v_{U+1}=0 .
$$

Якщо загальна кількість відсічених коренів $T$, а загальна кількість залишених гілок $-V$. Тоді

$$
\begin{gathered}
T=\sum_{j=1}^{T+1} t_{j}, \\
V=\sum_{j=1}^{T+1} v_{j}
\end{gathered}
$$

підсумовуючи $(5,6)$, отримаємо

$$
V=Z \frac{Z^{U+1}-1}{Z-1}-t_{1} \frac{Z^{U+1}}{Z-1}-t_{2} \frac{Z^{U}-1}{Z-1}-\ldots-t_{U+1} \frac{Z-1}{Z-1},
$$

або, помічаючи прийдемо до результату

$$
V=\frac{T-Z}{Z-1} .
$$

Вважаючи, що кількість залишилися гілок може бути інтерпретовано як довжина шляху, що веде до вирішення, отриманий результат можна сформулювати в наступній формі: довжина шляху, що веде до вирішення, залежить від співвідношення числа відсічених коренів і числа застосовуваних операторів.

Розуміючи надалі під ефективністю рішення $\Xi(\mathrm{U})$ відношення довжин шляхів до вирішення без використання $V^{*}$ і з використанням $(V)$ того чи іншого тексту, отримаємо

$$
\Xi(U)=\frac{V^{*}}{V} .
$$

Підставляючи отримане у (7) та у (8) отримали

$$
\Xi(U)=\frac{Z\left(Z^{U}-1\right)}{T-Z} .
$$

Знайдемо граничне значення $T$, через нього та $\Xi(U)[9,10]$.

1 варіант) $T_{\min }$ можливо, коли на кожному з $U$ етапів $є$ тільки один шлях, а на $(U+1)$-му етапі немає жодного шляху (так як рішення вже знайдено), тобто

Звідси слідує

$$
t_{1}=t_{2}=\ldots t_{U}=Z-1 ; m_{U+1}=Z \text {. }
$$

$$
T_{\min }=(Z-1) U+Z .
$$

2 варіант) $T_{\max }$ можливо, коли на кожному з $U$ етапів $\epsilon$ місце всіх шляхів, а на $U+l$-му а етапі всі шляхи відсічені, тобто

$$
m_{1}=m_{2}=\ldots m_{U}=0 ; m_{U+1}=Z^{U+1} .
$$

Звідси, $T_{\max }=Z^{U+1}$.

Підставляючи ці значення в рівність (8), отримаємо межі зміни ефективності рішення

$$
1 \leq \Xi(U) \leq \frac{Z}{U} \frac{\left(Z^{U}-1\right)}{Z-1} .
$$


Порахуємо далі ефективність рішення при використанні ієрархічної системи рішення.

Нехай передостанній рівень ієрархічної системи утворює $c$ підцілей (а, отже $c$ підетапом) об'єднуючих по $U^{\prime}$ операції останнього рівня.

Тоді

$$
U=c U^{\prime} \text {. }
$$

Загальне число гілок, ведучих до кожної з підцілей, відповідно до раніше сказаного буде

$$
\frac{Z\left(Z^{U}-1\right)}{Z-1}
$$

а загалі

або

$$
V^{* *}=\frac{Z\left(Z^{U^{\prime}}-1\right)}{Z-1} c
$$

$$
V^{* *}=\frac{Z\left(Z^{U^{\prime}}-1\right)}{Z-1} \frac{U}{U^{\prime}}
$$

Порівнюючи отриманий вираз з загальною кількістю шляхів до вирішення отримаємо

$$
\frac{V^{*}}{V^{* *}}=\frac{Z^{U}-1}{Z^{U^{\prime}}-1} \frac{T^{\prime}}{T}
$$

або, враховуючи що $Z^{U}>>1_{\text {та }} Z^{U^{\prime}}>>1$, отримаємо кінцевий вираз для методу оцінки ефективності моделей автоматизації контроля ТС 3ВТ [9]

$$
\frac{V^{*}}{V^{* * *}} \approx \frac{U^{\prime}}{U} Z^{U-U^{\prime}} .
$$

Висновки. Дослідження дозволяють зробити висновок про пріоритетність розвиту транспортної галузі для України. Варто підкреслити тенденцію постійного збільшення обсягу водного перевезення вантажів та інші успіхи. Але продовжує існувати проблема безпеки, яка пов'язана як з надійністю техніки, так ї з помилками персоналу та другими чинниками. За офіційними даними в 2017 році рівень аварійності на морському і річковому транспорті зріс на $68 \%$, а кількість загиблих осіб в аварійних подіях зменшилася на 50 \%, кількість травмованих осіб зменшилася на $75 \%$.

Аналіз показав місто та роль заходів по контролю технічного стану суден в різноманітних умовах експлуатації та шляхи підвищення ефективності даного процесу. А також місто даного завдання при вирішенні проблеми безпеки судноплавства. Визначена актуальність науково-практичних досліджень в даному напрямку.

Дослідження сучасних та перспективних систем автоматизації контролю технічного стану засобів водного транспорту, з урахуванням думки відомих вчених, визначають тенденцію, суть якої в тому, що на теперішній час можливості інтенсивного розвитку традиційних систем централізованого контролю технічних параметрів, в основному, вичерпалася. Подальше підвищення надійності і ефективності експлуатації суднової техніки вимагає розширеного застосування компонентів технічної діагностики для оцінки і прогнозування фактичного технічного стану обладнання. Тому найбільш перспективним напрямом удосконалення даних систем $\epsilon$ їх комплексування, інтеграція та впровадження відповідних нових моделей та методів в так званні «інтегровані мостикові систем управління судном».

Доведено, те що в умовах інтенсивного розвитку інформаційних технологій, які дозволяють вирішувати будь-які складні завдання за рахунок автоматизації прогресивною $є$ тенденція інтегрування та автоматизації всіх функцій на судні, в тому числі ї завдань контролю технічного стану судна. Також в роботі доведена сучасність та важливість існуючої тенденції створення інтегрованого обладнання ходової рубки, яка полягає в розробці так званої інтегрованої мостикової системи (Integrated Bridge System). Аналіз наукових та інженерних підходів створення та впровадження інтегрованих мостикових систем управління дозволів виявити рід системних недоліків та зауважень, а саме, відсутність функцій автоматизованого контролю технічного стану судна. 
Таким чином, наукове завдання розробці моделей та методів автоматизації контролю технічного стану засобів водного транспорту у різноманітних умовах експлуатації з метою впровадження їх в математичному та програмному забезпеченні AРM в Integrated Bridge System $\epsilon$ новим та актуальним.

Евристична модель оперативного визначення технічного стану засобів водного транспорту в умовах відсутності достовірної статистичної інформації, яка вперше розроблена, має відмінну особливість, суть якої у використані при опису процесу зміни стану ланцюжків причино-наслідкових зв'язків та продукційної моделі оператору переходу; це дозволяє значно скоротити обчислювальні витрати та час на визначення стану.

За результатами моделювання підтверджена достовірність наукових результатів.

\section{REFERENCES}

1. Aleksishin V.G., Kozyr L.A., Simonenko S.V. (2009). Obespechenie navigacionnoj bezopasnosti plavaniya: uchebnoe posobie. Odessa: Feniks. $518 \mathrm{~s}$.

2. Bogomya V.I., Davidov V.S., Doronin V.V., Pashkov D.P., Tihonov I.V. (2012). Navigacijne zabezpechennya upravlinnya ruhom suden. K.: DVVP «Kompas». $336 \mathrm{~s}$.

3. Kolomiyec O. M., Danik O. V. (2017). Ocinyuvannya vplivu zastosuvannya intelektualnoyi sistemi ekspluataciyi sudna na virishennya zavdan bezpeki. Standartizaciya, sertifikaciya, yakist. Vip. 2 (105). P. 75-78.

4. Kolomiyec O. M., Bogomya V. I. (2017). Metodi pidvishennya efektivnosti procesu ekspluataciyi sudnovih kompleksiv. Novitni tehnologiyi. Vip. 1(3). P. 42-48.

5. Kudricka N. V. (2010). Transportnodorozhnij kompleks Ukrayini: suchasnij stan, problemi ta shlyahi rozvitku: monografiya. Kiev: NTU. $338 \mathrm{~s}$.

6. Kolomiyec O. M., Timoshuk O.M., Daki O.A., Trofimenko I.V. (2017). Kriterij optimalnosti procesu tehnichnogo obslugovuvannya sudnovih kompleksiv/ Nauka i tehnika Povitryanih sil Zbrojnih sil Ukrayini. №4(29). P.132-136.

7. Kolomiyec O. M., Danik O. V., Daki O. A., Gorban A. V. (2018). Verifikaciya tehnologiyi ekspertnogo viznachennya ustupki mizh vartistyu ta efektivnistyu sistemi navigaciyi ta upravlinnya ruhom. Novitni tehnologiyi. Vip. 1(5). P. 29-42.

8. Kolomiyec O. M., Timoshuk O. M., Daki O. A. (2018). Obgruntuvannya zastosuvannya signaliv z normovanim spektrom dlya kontrolyu tehnichnogo stanu radionavigacijnih priladiv zasobiv vodnogo transportu. Novitni tehnologiyi. Vip. 2(6). P. 39-45.

9. Kolomiyec O. M., Vorobyov E. S., Shevchenko A. P., Mazur A. M. ta in. (2018). Razrabotka metodov szhatiya soobshenij o vozdushnyh obektah i upravleniya diskretnostyu ih vydachi ot istochnikov radiolokacionnoj informacii. Novitni tehnologiyi. Vip. 3(7). P. 217-230.

10. V.I. Bogomya, A.V. Gorban, M.A. Pavlenko, O.I. Timochko, O.M. Timoshuk. Za zag. red.O.M.T imoshuk. Osoblivosti sistemnogo pidhodu do virishennya naukovih zavdan ekspluataciyi sudnovogo obladnannya. Kiyiv. DUIT. 2018. 305 s. 